Rev. Inst. Flor. v. 26 n. 2 p. 161-167 dez. 2014

http://dx.doi.org/10.4322/rif.2014.012

ISSN impresso 0103-2674/on-line 2178-5031

\title{
VARIAÇÃO GENÉTICA PARA OS TEORES DOS MACRO E MICRONUTRIENTES APÓS APLICAÇÃO DE 2,4-D EM PROGÊNIES DE Eucalyptus grandis ${ }^{1}$
}

\section{GENETIC VARIATION IN THE LEVELS OF MACRO AND MICRONUTRIENTS AFTER 2,4-D APPLICATION ON Eucalyptus grandis PROGENIES}

\author{
Alexandre Martins FRAGOSO ${ }^{2,5}$; Edson Seizo MORI ${ }^{3}$; \\ Mario Luiz Teixeira de MORAES ${ }^{4}$
}

\begin{abstract}
RESUMO - O Brasil triplicou sua produção florestal de eucalipto desde 1970, alcançando médias de $45 \mathrm{~m}^{3} \cdot \mathrm{ha}^{-1}$.ano ${ }^{-1}$. Muitos avanços técnicos contribuíram para essa produtividade, entre eles a utilização de herbicidas para o controle de plantas daninhas. O produto 2,4-D destaca-se como herbicida seletivo às dicotiledôneas utilizado nas grandes culturas, entre elas está a cultura do eucalipto. O 2,4-D também pode ser usado como regulador vegetal, auxina (Ax), em subdosagem, podendo gerar incrementos nutricionais e auxiliar no desenvolvimento morfológico do vegetal após testes preliminares para obtenção de dosagem ideal, que no presente trabalho foi de $3,75 \mu \mathrm{L} \mathrm{L}^{-1}$. Assim, o trabalho teve como objetivos avaliar a aplicação de auxina em um teste de progênies de Eucalyptus grandis, na fase de mudas, para estimar os parâmetros genéticos das variações dos elementos minerais nas plantas, com base no procedimento REML/BLUP. O delineamento foi em blocos casualizados com 20 progênies em três repetições, 16 plantas por parcela, totalizando 960 plantas. Como fatores norteadores, após 15 dias da aplicação do produto, foram avaliados os macro e micronutrientes $(\mathrm{N}, \mathrm{P}, \mathrm{K}$, $\mathrm{Ca}, \mathrm{Mg}, \mathrm{S}, \mathrm{B}, \mathrm{Cu}, \mathrm{Fe}, \mathrm{Mn}$ e $\mathrm{Zn}$ ) nos tecidos vegetais da parte aérea. Como resultado, verificou-se que o 2,4-D age como auxina, quando aplicada em subdosagem $\left(3,75 \mu \mathrm{L} \mathrm{L}^{-1}\right)$, promovendo o desenvolvimento das mudas de $E$. grandis e permite a expressão da variação genética, sendo que o $\mathrm{CV}_{\mathrm{g}}$ variou de $1,22 \%(\mathrm{~S})$ a $13,51 \%(\mathrm{Ca})$. Apenas os teores de $\mathrm{N}(43,05 \%)$, $\mathrm{Fe}(56,545 \%)$ e $\mathrm{Cu}(58,37 \%)$ apresentaram acurácias inferiores a $70 \%$. Os maiores coeficientes de variação relativa foram para os teores de $\mathrm{Ca}(2,0)$ em relação à escolha de uma variável para a seleção com base nos macronutrientes e Mn $(1,16)$ no caso dos micronutrientes.
\end{abstract}

Palavras-chave: auxina; metabolismo; nutrição mineral; parâmetros genéticos.

\begin{abstract}
The forest tree production in Brazil was three times greater than through 70's decade, reaching the wood volume averages by $45 \mathrm{~m}^{3} \cdot \mathrm{ha}^{-1} . \mathrm{year}^{-1}$. Many technological advances have contributed for that productivity, such as the use of herbicides for weed control, thus avoiding much of the weed competition and better development of plants as the lighting and nutrient assimilation. The 2,4-D product stands out as selective herbicide for broadleaved used in major crops, among them is the cultivation of eucalyptus. The 2,4-D may also be used as plant growth regulator as a synthetic auxin $(\mathrm{Ax})$ and can generate nutritional helper increases and the morphological plant development after preliminary testing to obtain optimal dosage.
\end{abstract}

\footnotetext{
${ }^{1}$ Recebido para análise em 14.04.14. Aceito para publicação em 13.10.14

${ }^{2}$ Faculdade de Ciências Agronômicas - FCA/UNESP, Fazenda Lageado, Portaria I, Rua José Barbosa de Barros, nº 1780 , Rodovia Alcides Soares, Km 3 , 18610-307 Botucatu, SP, Brasil. Bolsista CAPES.

${ }^{3}$ Faculdade de Ciências Agronômicas - FCA/UNESP, Departamento de Produção e Melhoramento Vegetal, Campus de Botucatu, Fazenda Experimental Lageado, Rua José Barbosa de Barros, 1780, Caixa Postal 237, 18610-307 Botucatu, SP, Brasil. esmori@fca.unesp.br.

${ }^{4}$ Faculdade de Engenharia de llha Solteira, Departamento de Fitotecnia, Tecnologia de Alimentos e Sócio-Economia, Rua Monção, n 226 , Zona Norte, 15385-000 Ilha Solteira, SP, Brasil. teixeira@agr.feis.unesp.br.

${ }^{5}$ Autor para correspondência: Alexandre Martins Fragoso - amfragozo@hotmail.com
} 
This study aimed to evaluate the influence and interactions between obtaining optimal doses of 2,4-D product as plant growth regulator through the Eucalyptus grandis progeny trial to estimate quantitative genetic parameters. We used statistical design of randomized blocks with 20 progenies, and three replications with 16 plants, totaling 960 plants by the trial. The quantitative genetic parameters were obtained by SELEGEN software using REML/BLUP statistical procedure. As guiding factors after 15 days of application of 2,4-D doses, we have evaluated macro and micronutrients $(\mathrm{N}, \mathrm{P}, \mathrm{K}, \mathrm{Ca}, \mathrm{Mg}, \mathrm{S}, \mathrm{B}, \mathrm{Cu}, \mathrm{Fe}$, $\mathrm{Mn}$, and $\mathrm{Zn}$ ) in aerial part of plant tissues. As a result it was found that 2,4-D in sub-dosage $\left(3.75 \mu \mathrm{L} . \mathrm{L}^{-1}\right)$ promoted the development of $E$. grandis and allows the expression of genetic variation, the $\mathrm{CVg}$ ranged from $1.22 \%(\mathrm{~S})$ to $13.51 \%(\mathrm{Ca})$. Only the $\mathrm{N}$ levels $(43.05 \%)$, $\mathrm{Fe}(56.545 \%)$ and $\mathrm{Cu}(58.37 \%)$ showed lower accuracies below 70\%. The highest coefficients of relative variation were related for $\mathrm{Ca}(2.0)$ as selection factor for selection based on macronutrients and Mn (1.16) on micronutrients.

Keywords: auxin; genetic parameters; metabolism; mineral nutrition.

\section{INTRODUÇÃO}

Com o desenvolvimento agrícola, os insumos vêm sendo utilizados em larga escala, onde os avanços nas áreas técnicas da cadeia agrícola vêm diminuindo as perdas e maximizando os ganhos, principalmente aqueles relacionados à produtividade e uso de novas tecnologias. Produtividade esta que, alcançada pelas grandes culturas, entre elas a do eucalipto, torna necessário o uso racional dos produtos, entre eles os fitossanitários, como os herbicidas.

Para a incorporação de novas tecnologias no âmbito florestal, as mesmas devem ser comprovadas por meio de experimentos como os testes de progênies, nos quais são avaliados as características de interesse e as demais relacionadas ao processo produtivo, pois quanto maiores forem os ganhos na espécie a ser melhorada, melhor serão as condições de adaptabilidade ao local de plantio e maior será a resistência a fatores não controlados, generalizados nas características de sobrevivência do vegetal ao estresse. Estresse caracterizado pela severidade, duração, tempo de exposição e combinação deles, nos quais os tecidos, genótipos e estádio de desenvolvimento do vegetal irão determinar a resposta e o resultado, ou seja, se haverá a tolerância (sobrevivência) ou suscetibilidade (morte) do vegetal (Fragoso, 2014).

O 2,4-D vem sendo utilizado desde a guerra do Vietnã como agente desfolhante, bem como o ácido 2,4,5-triclorofenoxiacético (2,4,5-T) e o pentaclorofenol (PCF), para formação do até então denominado "agente laranja" (Taiz, 2013). Atualmente, o produto DMA é um herbicida sistêmico e seletivo para a cultura da cana-de-açúcar, cereais, pomares e no controle florestal. Deve ser aplicado em pós-emergência, controlando seletivamente as plantas de folhas largas, as plantas dicotiledôneas. Sua aplicação dá-se em função do estádio fenológico da cultura, seguindo as recomendações do boletim técnico Down Agrosciences para as respectivas culturas. Os estudos com relação à molécula, caracterizada como regulador vegetal auxina, baseiam-se nos estudos deletérios de derivas artificiais, que têm causado modificações em culturas agrícolas comestíveis, deixando efeitos residuais no solo (Hemphill e Montgomery, 1981; Wall, 1996; Constantin et al., 2007; Reis et al., 2008; Nascimento e Yamashita, 2009).

A metodologia de utilização de 2,4-D como regulador para culturas anuais e perenes, destacando-se que o ponto de epinastia é aquele no qual se dividem as demais doses decrescentes gradativas para obtenção de dose ideal, indicando que a dosagem de plantas perenes é relativamente dez vezes maior que as anuais para o produto 2,4-D (Fragoso et al., 2012a). Os ganhos significativos para a área foliar e matéria seca em E. grandis, nas quais a dosagem de $2,5 \mathrm{mg}$.i.a. $\mathrm{L}^{-1}$ foi a significativa, indicam alterações na fotossíntese e demais alterações no metabolismo do vegetal (Fragoso et al., 2012b). Assim, observações em E. grandis com medições na altura e diâmetro apresentaram outro efeito, o de alongamento celular, pois na dosagem de 0,625 mg.i.a. $\mathrm{L}^{-1}$ ganhos na altura e diâmetro foram observados, indicando que alterações endógenas nos níveis de auxina são alteradas com a aplicação do produto (Fragoso et al., 2012c). 
Desse modo, a importância nutricional da interação com o produto, no qual os elementos fósforo e enxofre apresentaram diferenças significativas na dosagem de $3,75 \mu \mathrm{L} . \mathrm{L}^{-1}$, indicam a participação dos elementos na fotossíntese, como ATP e cofatores enzimáticos, respectivamente (Fragoso et al., 2013). Assim, fica evidente que o vegetal sob condição de estresse pode alterar seu metabolismo, tendo em vista sua sobrevivência ou devido a um ganho por processos biológicos da interação como abertura estomática, fotossíntese e elongação celular.

O teste de progênies tem como finalidade, relacionada a valores reprodutivos, estimar parâmetros genéticos, sendo todos os indivíduos avaliados com características de sua morfologia como altura, diâmetro e volume (Moraes, 2001). A especificidade relacionada ao tipo de polinização, torna o teste gradativo de dificuldade, facilitando ou não, a seleção recorrente dos indivíduos (Daniels, 1984), sendo que a avaliação da capacidade produtiva permite a extrapolação dos resultados até então obtidos, possibilitando novas características na população a ser melhorada e obtenção de indivíduos superiores para produção, ou com alto valor genético, para conservação.

A capacidade de identificação de genótipos superiores sob um programa de seleção, torna possível a obtenção de populações melhoradas (Kageyama, 1980). As estratégias de melhoramento baseiam-se nas estimativas de parâmetros genéticos e predição de ganhos, pois as mesmas geram informações sobre o potencial genético do indivíduo, progênies e clones, para a obtenção de um novo ciclo de seleção (Resende, 1991; Fernandes et al., 2004).

O presente estudo teve como hipótese se a utilização de subdosagens de 2,4-D em mudas de Eucalyptus grandis teria efeito na translocação de nutrientes à parte aérea (Schoroder et al., 1983; Reis et al., 2008), onde ocorreria uma melhor translocação de produtos sistêmicos, aumentando a sua eficiência, possibilitando subadubações, sistêmicas e racionais, além de incrementos produtivos por aumento da taxa fotossintética por alteração do metabolismo. Desse modo, as mudas teriam maior estímulo de crescimento em função da interação com o produto e resposta a sobrevivência, por parte do vegetal, ao estresse imposto.
Assim, o comportamento do 2,4-D, como uma auxina, é um evento fisiológico, mas a presença dos teores dos macro e micronutrientes é de origem genética e a estimativa desta variação é significativa para o desenvolvimento da planta em diferentes ambientes.

$\mathrm{Na}$ falta de trabalhos sobre a utilização do herbicida 2,4-D como regulador, utilizando a cultura do Eucalyptus grandis como cultura pioneira de estudo e sua interação nos níveis nutricionais (N, P, K, Ca, Mg, S, B, Cu, Fe, Mn e Zn) de tecidos vegetais da parte aérea, surgiu a proposta do presente trabalho, que teve por objetivo avaliar a variação genética dos teores dos macros e micronutrientes após a aplicação de subdosagens de 2,4-D em progênies de E. grandis na fase final de mudas.

\section{MATERIAL E MÉTODOS}

O estudo foi realizado na Fazenda Experimental Lageado, pertencente à Faculdade de Ciências Agronômicas - FCA, da Universidade Estadual Paulista - UNESP. A FCA localiza-se na região centro-sul do Estado de São Paulo, cujas coordenadas são $22^{\circ} 51^{\prime} 03^{\prime \prime}$ de latitude Sul e 48 $25^{\prime} 37^{\prime \prime}$ de longitude Oeste, com altitude de 804 m. Segundo a classificação Köppen, o clima é do tipo Cfa - moderado chuvoso, sendo a temperatura média do ar de $22,8{ }^{\circ} \mathrm{C}$ no mês mais quente, e de $16,7{ }^{\circ} \mathrm{C}$ no mês mais frio, com média anual de 20,6 ${ }^{\circ} \mathrm{C}$ (Cunha e Martins, 2009).

O experimento foi instalado em 10 de outubro de 2013, no viveiro de mudas do Departamento de Ciências Florestais da Faculdade de Ciências Agronômicas/UNESP - Campus de Botucatu/SP. O teste de progênies de Eucalyptus grandis foi implantado em delineamento em blocos ao acaso, 16 plantas por parcela, três repetições e 20 progênies de Eucalyptus grandis, originárias do Horto Florestal de Itatinga, totalizando 960 plantas. A dose de 2,4 D foi de $3,75 \mu \mathrm{L} . \mathrm{L}^{-1}$. A aplicação do produto ocorreu nas seguintes condições: Altura da planta: 0,30 m; Altura da barra: 0,90 m; Volume aplicado: 110 L.ha $^{-1}$; Pressão: 1,95 bar; Velocidade: $5 \mathrm{~km} . \mathrm{h}^{-1}$; Umidade relativa: $65 \%$; Temperatura: $26^{\circ} \mathrm{C}$; Ponta XR 110015 US. 
As variáveis analisadas foram os teores dos macro e micronutrientes (Malavolta, 1997), cujas análises foram realizadas no laboratório do Departamento de Recursos Naturais - Ciência do Solo, da Faculdade de Ciências Agronômicas da UNESP Botucatu-SP (cinco plantas por parcela amostra composta). Retiraram-se todas as mudas em amostras destrutivas para as análises, sem observação de toxicidade e comportamento do vegetal após a aplicação de produto. As estimativas dos parâmetros genéticos para caracteres quantitativos foram obtidas com base no procedimento REML/BLUP e foi utilizado o programa computacional SELEGEN (Resende, 2007b), com base no modelo estatístico: $\mathrm{y}=\mathrm{Xr}+\mathrm{Zg}+\varepsilon$; em que: $y, r, g$, e $\varepsilon$ são vetores de dados, repetição genéticos aditivos individuais, de parcelas $\mathrm{e}$ de erros, respectivamente; $\mathrm{X}$ e $\mathrm{Z}$ são matrizes de incidência dos respectivos efeitos (Resende, 2007a). A partir desse modelo foi possível obter as seguintes estimativas:

Variância residual (ambiental + não aditiva): $\hat{\sigma}_{e}^{2}$

Variância genotípica: $\hat{\sigma}_{g}^{2}$

Variância fenotípica individual: $\hat{\sigma}_{f}^{2}=\hat{\sigma}_{g}^{2}+\hat{\sigma}_{e}^{2}$

Variância fenotípica média: $\hat{\sigma}_{f m}^{2}=\hat{\sigma}_{e}^{2} / \mathrm{r}+\hat{\sigma}_{p}^{2}$

Coeficiente de variação experimental: $C V_{e}=\left(\sqrt{Q M_{e}} / \hat{m}\right) \cdot 100$

Coeficiente de variação genotípica: $C V_{g}=\left(\sqrt{\hat{\sigma}_{g}^{2}} / \hat{m}\right) \cdot 100$

Coeficiente de variação relativa $\left(\mathrm{CV}_{r}\right): \mathrm{CV}_{r}=\mathrm{CV}_{g} / \mathrm{CV}$.

Coeficiente de herdabilidade de parcelas individuais no sentido amplo $\left(\hat{h}_{g}^{2}\right): \hat{h}_{g}^{2}=\hat{\sigma}_{g}^{2} / \hat{\sigma}_{f}^{2}$

Coeficiente de herdabilidade da média de genótipo $\left(\hat{h}_{m}^{2}\right): \hat{h}_{m}^{2}=\hat{\sigma}_{p}^{2} / \hat{\sigma}_{f m}^{2}$

Acurácia: $\hat{r}_{a a}=\sqrt{\hat{h}_{m}^{2}}$

\section{RESULTADOS E DISCUSSÃO}

$\mathrm{Na}$ avaliação da parte aérea das mudas de Eucalyptus grandis, avaliado duas semanas após a aplicação de 2,4-D na dose de 3,75 $\mu \mathrm{L}^{\mathrm{L}} \mathrm{L}^{-1}$, verificou-se que a maioria dos teores dos elementos analisados (P, K, Ca, Mg, S, Mn e Zn) apresentou variação para o efeito de progênies, com base no teste da razão de verossimilhança (LRT), indicando que estes teores seriam passíveis de uma seleção em um programa de melhoramento, destacando-se os teores de $\mathrm{Ca}(\mathrm{CVr}=2,00)$ em relação aos macronutrientes e o manganês $(\mathrm{CVr}=1,16)$. $\mathrm{O}$ mesmo já não ocorreu em relação aos teores de N, B, Cu e Fe (Tabela 1).

O nitrogênio alcançou o nível mais baixo do teste para herdabilidade. Sua proporção da variância genética na variância fenotípica das amostras de tecidos da parte aérea, ligados às gerações seguintes da etapa de melhoramento (Resende, 2007a), se deu em função do possível consumo em fazer parte da molécula de clorofila. Indicando aumento da taxa fotossintética, com possível relação à abertura estomática, metabolismo de auxina e indicação de grande dependência ambiental (Tabela 1).

O cálcio apresentou a maior herdabilidade das amostras de tecidos da parte aérea, demonstrando ser um caráter altamente herdável em função principalmente do aumento na área foliar, por participar no aumento nos níveis celulares e estar relacionado à constituição da parede celular, indicando que a parte genética é superior a ambiental (Resende, 2007a).

O fósforo atuou na molécula de adenosina trifosfato (ATP), integrante do DNA, RNA e fosfolipídeos. O potássio agiu no potencial osmótico e transporte por membrana neutralizando ânions. O magnésio atuou na molécula de clorofila e ativação de enzimas e manganês constituinte do fotossistema II da fotossíntese (Epstein e Bloom, 2004). Esses apresentaram herdabilidades médias, indicando que em função da molécula do possível produto sistêmico a ser abordado, o mesmo poderá ser utilizado com caráter amplo nas progênies em função dos caracteres herdáveis, indicando pequena a influência ambiental na variação total (Resende, 2007a).

Em se tratando de herdabilidades médias de progênies, os níveis de fósforo, potássio, cálcio, magnésio e manganês apresentaram elevados índices indicando que, entre eles, cálcio com 0,92 é o de maior notoriedade também em nível de progênies.

Nitrogênio, cobre e ferro alcançaram as menores acurácias, nas quais a possível seleção por estes elementos se tornaria prejudicada e subestimada em relação aos demais que, em média, alcançaram valores superiores a 0,7273 . 
FRAGOSO, A.M.; MORI, E.S.; MORAES, M.L.T. de. Uso de 2,4-D como regulador de crescimento

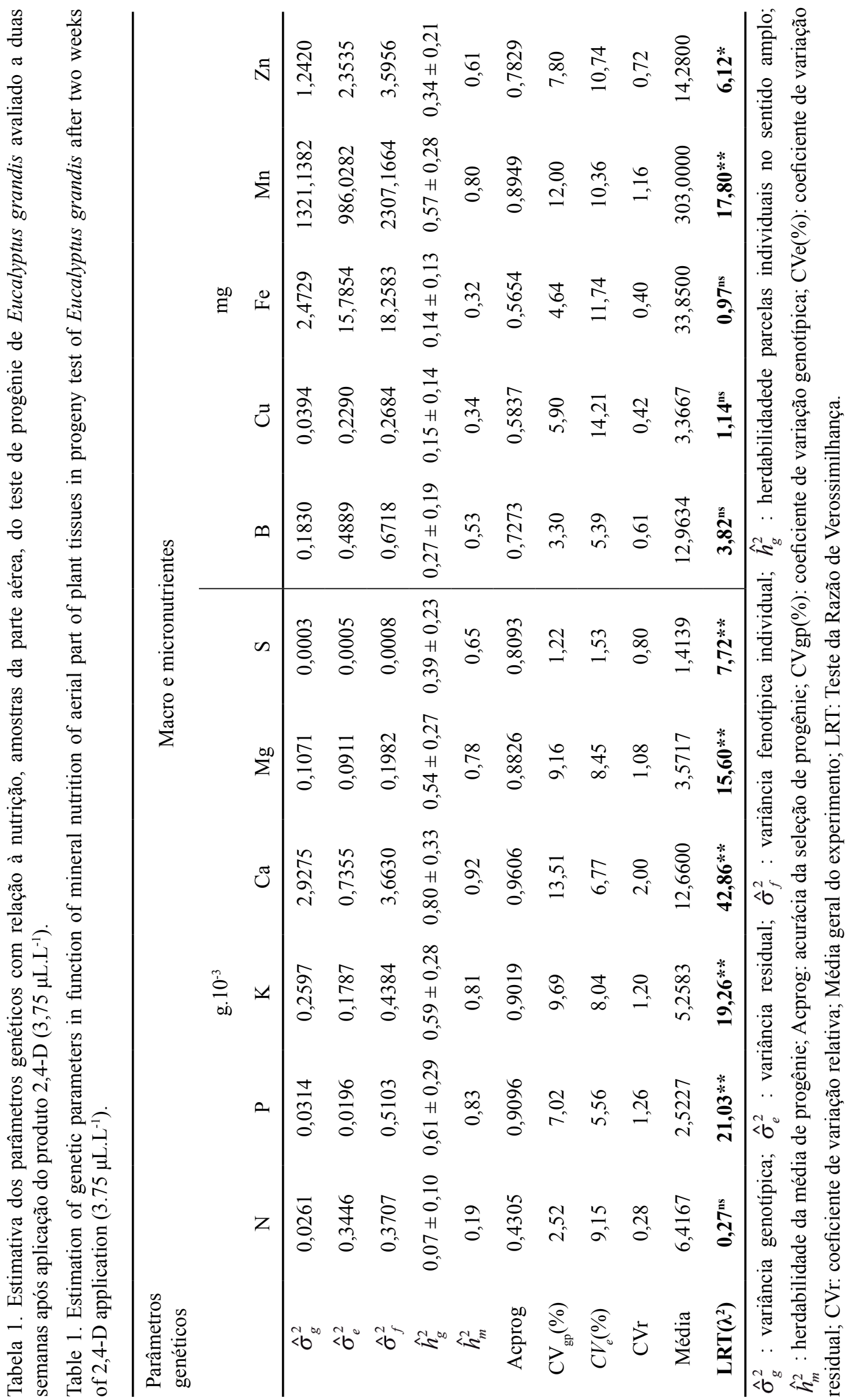


O coeficiente de variação genética entre progênies demonstrou alta variação no caráter ferro, porém com relação negativa aos demais parâmetros. O caráter de notoriedade seria o elemento cálcio, com 13,51, indicando que há variabilidade genética.

Porém, com $C V_{r}$ de 2,00 o elemento cálcio se destacou entre os demais neste fator, classificando-se como norteador da interação do regulador vegetal com a cultura, para servir de padrão envolvendo os estudos de melhoramento (Vencovsky, 1969). Quanto maior for o CVr, este indica o fator norteador de avaliação dos experimentos de Eucalyptus grandis com subdosagens de 2,4-D.

As herdabilidades junto as acurácias comprovam valores excelentes, indicando eficiência de uma seleção geral envolvendo o teste de progênie, caracterizando uma situação favorável à seleção destes caracteres.

A maioria das correlações genéticas (Tabela 2) foi de baixa magnitude. No entanto, destacam-se nessa fase (duas semanas após a aplicação de 2,4-D em mudas de E. grandis) as correlações entre os teores dos elementos: P x K $(0,75)$; Ca x Mn $(0,75)$ e $\mathrm{Ca} \times \mathrm{Mg}(0,70)$.

Tabela 2. Correlações genéticas de macro (g.10-3) e micronutrientes (mg) da parte aérea após duas semanas de aplicação de 2,4-D em progênies de Eucalyptus grandis.

Table 2. Genetic correlations of macro $\left(\mathrm{g} .10^{-3}\right)$ and micronutrients $(\mathrm{mg})$ of aerial parts after two weeks of 2,4-D application in Eucalyptus grandis progenies.

\begin{tabular}{lcccccccccc}
\hline & $\mathrm{P}$ & $\mathrm{K}$ & $\mathrm{Ca}$ & $\mathrm{Mg}$ & $\mathrm{S}$ & $\mathrm{B}$ & $\mathrm{Cu}$ & $\mathrm{Fe}$ & $\mathrm{Mn}$ & $\mathrm{Zn}$ \\
\hline $\mathrm{N}$ & 0,29 & 0,44 & $\mathbf{0 , 5 8}$ & 0,36 & $-0,14$ & 0,15 & 0,33 & 0,00 & 0,40 & $-0,14$ \\
$\mathrm{P}$ & - & $\mathbf{0 , 7 5}$ & 0,31 & 0,30 & 0,38 & $\mathbf{0 , 5 7}$ & 0,24 & $-0,22$ & 0,38 & $-0,42$ \\
$\mathrm{~K}$ & - & - & 0,21 & 0,33 & 0,18 & $\mathbf{0 , 6 0}$ & 0,15 & $-0,11$ & 0,38 & $-0,28$ \\
$\mathrm{Ca}$ & - & - & - & $\mathbf{0 , 7 0}$ & 0,11 & 0,07 & $\mathbf{0 , 5 0}$ & 0,06 & $\mathbf{0 , 7 5}$ & $-0,03$ \\
$\mathrm{Mg}$ & - & - & - & - & 0,48 & 0,34 & 0,06 & 0,33 & 0,67 & 0,20 \\
$\mathrm{~S}$ & - & - & - & - & - & 0,36 & 0,18 & 0,14 & 0,16 & 0,33 \\
$\mathrm{~B}$ & - & - & - & - & - & - & $-0,15$ & $-0,16$ & 0,34 & 0,00 \\
$\mathrm{Cu}$ & - & - & - & - & - & - & - & $-0,23$ & 0,32 & $-0,16$ \\
$\mathrm{Fe}$ & - & - & - & - & - & - & - & - & 0,01 & $\mathbf{0 , 5 1}$ \\
$\mathrm{Mn}$ & - & - & - & - & - & - & - & - & - & $-0,22$ \\
\hline
\end{tabular}

\section{CONCLUSÕES}

A expressão da variação genética para os teores dos macro (N, P, K, Ca, Mg e S) e micronutrientes (B, $\mathrm{Cu}, \mathrm{Fe}, \mathrm{Mn}$ e $\mathrm{Zn}$ ), na fase de mudas, é considerável em progênies de E. grandis, após aplicação do 2,4-D em subdosagem.

Em relação aos teores dos macronutrientes, recomenda-se a utilização do teor de $\mathrm{Ca}$ como a variável a ser selecionada para a obtenção de um maior ganho na seleção; no que se refere aos micronutrientes, à indicação fica para o teor de $\mathrm{Mn}$.

\section{AGRADECIMENTOS}

À Coordenação de Aperfeiçoamento de Pessoas de Nível Superior - CAPES, pela concessão da bolsa de estudo.

\section{REFERÊNCIAS BIBLIOGRÁFICAS}

CONSTANTIN, J. et al. Efeito de subdoses de 2,4-D na produtividade de fumo e suscetibilidade da cultura em função de seu estádio de desenvolvimento. Eng. Agríc., v. 27, p. 30-34, 2007.

CUNHA, A.R.; MARTINS, D. Classificação climática para os municípios de Botucatu e São Manuel, SP. Revista Irriga, v. 14, n. 1, p. 1-11, 2009. 
DANIELS, J.D. Role of tree improvement in intensive forest management. Forest Ecology and Management, v. 8, n. 3/4, p. 161-165, 1984.

EPSTEIN, E.; BLOOM, A. Nutrição mineral de plantas: princípios e perspectivas. Londrina: Planta, 2004. 403 p.

FERNANDES, J.S.C. et al. Estudo comparativo de delineamentos experimentais para estimativas de parâmetros genéticos em erva-mate (Ilex paraguariensis A. St. - Hil.). Revista Árvore, v. 28, n. 5, p. 663-671, 2004.

FRAGOSO, A.M. Variações nos níveis de elementos minerais após aplicações de 2,4-D em progênies de Eucalyptus grandis. 2014. 48 f. Dissertação (Mestrado em Ciências Florestais), Faculdade de Ciências Agronômicas, Universidade Estadual Paulista "Júlio de Mesquita Filho", Botucatu.

et al. Efeito do 2,4-D na translocação de nutrientes na cultura do feijoeiro. In: MOSTRA CIENTÍFICA EM CIÊNCIAS AGRÁRIAS, 7., Botucatu, 2011. Disponível em:<www.fca.unesp.br/ Home/Pesquisa/MostraCientifica/trabs/57.pdf $>$. Acesso em: 5 fev. 2014.

. et al. Utilização de 2,4-D como biorregulador. In: MOSTRA CIENTÍFICA EM CIÊNCIAS AGRÁRIAS, 8., Botucatu, 2012a. Disponívelem: $<$ www.fca.unesp.br/Home/Pesquisa/ .../inscricao/.../1347639226trab.dot>. Acesso em: 5 fev. 2014.

(2,4-D) na área foliar e matéria seca em eucalipto. In: CONGRESSO DE BIOCIÊNCIAS, Botucatu, 2012b. Disponível em: <www.ibb.unesp.br/\#!/ eventos/congresso-de-biociencias/resumos $>$. Acesso em: 9 nov 2012.

. et al. 2,4-D em sub-dosagens em Eucalyptus grandis. In: CONINCE, 5., Avaré, 2012c. Disponível em: <www.eduvaleavare.com. br/conince/resumos $>$ Acesso em: 1 jan 2013.

. et al. Metabolismo fisiológico de 2,4-D em Eucalyptus grandis. In: CONINCE, 6., Avaré, 2013. Disponível em: <www.eduvaleavare.com.br/ conince/resumos>. Acesso em: 1 fev 2014.

HEMPHILL, D.D.; MONTGOMERY, M.L. Response of vegetable crops to sublethal application of 2,4-D. Weed Science, v. 29, p. 632-635, 1981.
KAGEYAMA, P.Y. Variação genética em progênies de uma população de Eucalyptus grandis (Hill) Maiden. 1980. 125 f. Tese (Doutorado em Genética e Melhoramento de Plantas) - Escola Superior de Agricultura "Luiz de Queiroz", Universidade de São Paulo, Piracicaba.

MALAVOLTA, E.; VITTI, G.C.; OLIVEIRA, S.A. Avaliação do estado nutricional das plantas: princípios e aplicações. 2. ed. Piracicaba: Potafós, 1997. $319 \mathrm{p}$.

MORAES, M.L.T. Variação genética e aplicação da análise multivariada em progênies de Pinus caribaea Morelet var. hondurensis Barret e Golfari. 2001. 124 f. Tese (Livre Docência) Faculdade de Engenharia, Universidade Estadual Paulista, Ilha Solteira.

NASCIMENTO, E.R.; YAMASHITA, O.M. Desenvolvimento inicial de olerícolas cultivadas em solos contaminados com resíduos de 2,4-D + picloram. Ciências Agrárias, v. 30, n. 1, p. 47-54. 2009.

REIS, M.R. et al. Dinâmica de nutrientes em tecidos foliares de cana-de-açúcar após aplicação de herbicidas. Planta Daninha, v. 26, n. 1, p. 175-184, 2008.

RESENDE, M.D.V. Correções nas expressões do progresso genético com seleção em função da amostragem finita dentro de famílias de populações e implicações no melhoramento florestal. Boletim Pesquisa Florestal, n. 22/23, p. 61-77, 1991.

Matemática e estatística na análise de experimentos e no melhoramento genético. Colombo: Embrapa Florestas, 2007a. 362 p.

Software SELEGEN-REML/BLUP: sistema estatístico e seleção genética computadorizada via modelos lineares mistos. Colombo: Embrapa Florestas, 2007b. 359 p.

TAIZ, L.; ZEIGER, E. Fisiologia vegetal. 5. ed. Porto Alegre: Artmed, 2013. 954 p.

VENCOVSKY, R., Genética quantitativa. In: KERR, W.E. Melhoramento e genética. São Paulo: Melhoramentos: Editora da Universidade de São Paulo, 1969. p. 17-38.

WALL, D.A. Effect of sublethal dosages of 2,4-D on annual broadleaf crops. Canadian Journal of Plant Science, v. 76, n. 1, p. 179-85, 1996. 